\title{
Fisiopatología del daño multiorgánico en la infección por SARS-CoV-2
}

\section{Pathophysiology of multi-organ damage in SARS-CoV-2 infection}

\author{
Gerardo Tiburcio López-Pérez, ${ }^{1}$ María de Lourdes Patricia Ramírez-Sandoval, ${ }^{2}$ Mayra Solyenetzin \\ Torres-Altamirano ${ }^{3}$
}

\begin{abstract}
Resumen
La glucoproteína S del SARS-CoV-2 se une a la enzima convertidora de la angiotensina 2 (ACE2). El genoma del virus codifica cuatro proteínas estructurales esenciales: glucoproteína espiga, proteína de envoltura pequeña, proteínas matrices y proteína de nucleocápside. Se expresa más en hombres, quizá por el estradiol y la testosterona.

En la viremia pasa de las glándulas salivales y membranas mucosas, especialmente nasal y laringe, a los pulmones y a otros órganos con los mismos receptores ACE2: corazón, hígado e, incluso, al sistema nervioso central; llega a los intestinos, lo que puede explicar los síntomas; se detecta en las heces desde el inicio de la infección.

La coexistencia de hipertensión arterial sistémica, diabetes mellitus o neumopatías crónicas, obesidad o tabaquismo, inmunodeficiencias y la senescencia son clave en la patogénesis viral. Cuando el sistema inmunológico es ineficiente en controlar efectivamente al virus en la fase aguda, puede evolucionar a un síndrome de activación de macrófagos que da pie a la temida tormenta de citocinas que pone al paciente en un estado crítico.
\end{abstract}

Entender la fisiopatogenia de la infección por SARS-CoV-2 es la piedra angular para establecer el diagnóstico oportuno e implementar el tratamiento adecuado y limitar la propagación del virus y, en última instancia, eliminarlo.

PALABRAS CLAVE: SARS-CoV-2; entrada viral; genoma del virus; proteínas estructurales esenciales; ACE2; estradiol; testosterona; viremia; síndrome de activación de macrófagos; interacciones microbianas del huésped; síndrome respiratorio agudo severo

\section{Abstract}

SARS-CoV-2 could originate from unknown bats or intermediate hosts and cross the species barrier to humans. Virus-host interactions affect viral entry and replication. The virus genome encodes four essential structural proteins, the spike glycoprotein, the small envelope protein, the matrix proteins, and the nucleocapsid protein. The SARS$\mathrm{CoV}-2$ glycoprotein $\mathrm{S}$ binds to the host cell receptors of the enzyme, the conversion of angiotensin 2 (ACE2), which is a critical step for virus entry. It is expressed more in men than in women, probably by estradiol and testosterone that can influence ACE activity in different ways. In the viremia phase, it passes from the salivary glands and mucous membranes, especially the nasal and larynx, to the lungs and other organs with the same ACE2 receptors, such as the heart, liver, and even the central nervous system. It can reach the intestines, which can explain the symptoms and is detected in the stool from the beginning of the infection. Comorbidities such as immunodeficient status, old age, systemic arterial hypertension, diabetes mellitus or chronic lung diseases, obesity or smoking are key to viral pathogenesis. When the immune system is inefficient to effectively control the virus in the acute phase, it can evolve into a macrophage activation syndrome that results in the dreaded cytokine storm that puts the patient in a very critical condition. Understanding the pathophysiology of SARS-CoV-2 infection is the cornerstone to provide timely diagnosis and implement appropriate treatment for patients, limiting the spread of the virus and ultimately eliminating the presence of the virus in humanity.

KEYWORDS: SARS-CoV-2; Viral entry; Virus Genome; Nucleocapsid Protein; ACE2; Estradiol; Testosterone; Viremia; Macrophage Activation Syndrome; Host Microbial Interactions; Severe Acute Respiratory Syndrome.

\footnotetext{
1 Alergólogo, infectólogo, pediatra. Jefe del servicio de Alergia, Instituto Nacional de Pediatría.

2 Pediatra e infectóloga, adscrita al Hospital General de Z 32, IMSS.

${ }^{3}$ Odontopediatra, ortodoncista, ortopedista maxilar, egresada del Instituto Nacional de Pediatría, Directora médica de Asistencia Pediátrica Integral.
}

Recibido: 10 de mayo de 2020

Aceptado: 26 de mayo de 2020

Correspondencia

Gerardo Tiburcio López Pérez

apiger3@gmail.com

Este artículo debe citarse como López-Pérez GT, Ramírez-Sandoval MLP, Torres-Altamirano MS. Fisiopatología del daño multiorgánico en la infección por SARS-CoV-2.Acta Pediatr Méx 2020; 41 (Supl 1):S27-S41. 


\section{INTRODUCCIÓN}

El sistema inmunológico del humano es un sistema perfecto que combina toda una gama de células y mediadores para brindar inmunidad protectora contra los agentes infecciosos. Su intervención puede ser con reacciones tempranas, como en la inmunidad innata y, después, en un conjunto de respuestas celulares y humorales (inmunidad adaptativa), ambas decisivas en la defensa contra los gérmenes intracelulares, como el SARS-CoV-2.

Todas esas funciones se llevan a cabo en el paciente inmunológicamente normal durante la infección por SARS CoV-2 con el propósito de combatirla sin complicaciones, incluso, permanecer asintomático pero con posibilidad de contagio. Esto no sucede así en los ancianos, en las embarazadas o en quienes tienen alguna inmunodeficiencia primaria o secundaria (VIH-SIDA) y, por supuesto, en los diabéticos, individuos con síndrome metabólico, obesidad, inmunosupresión, neumopatía crónica o adicción al tabaco. Para poder intervenir apropiadamente, el clínico debe conocer las bases fisiopatogénicas de esta infección que ha dado pie a la pandemia de COVID-19.

\section{Patogenia}

La interacción entre el virus y el hospedero es decisiva porque depende de la condición de salud del afectado.

\section{Entrada del SARS-CoV-2 al hospedero}

El origen de todas las alteraciones clínicas de los pacientes con infección por SARS-CoV-2 se inicia con la unión de la glucoproteína $S$ al receptor de la célula huésped (enzima convertidora de angiotensina 2 [ACE2]), que es un paso crítico para la entrada del virus. También interviene una molécula activadora que facilita la invaginación de la membrana para la endocitosis de SARS-CoV-2 (proteasa celular transmembrana de serina tipo 2 [TMPRSS2]). ${ }^{1}$

Gran cantidad de los eventos inmunológicos que se observan en SARS-CoV-2 surgen a partir del conocimiento de la infección por SARS-CoV, con quien tiene una similitud en sus secuencias genéticas de 79\%; sin embargo, es más parecido al coronavirus de murciélago RaTG13, con 98\% de semejanza y a las secuencias del coronavirus del pangolín (un oso hormiguero escamoso). ${ }^{2}$

La ACE2 se encuentra en el riñón, sistema cardiovascular, hígado y tubo digestivo, sistema nervioso central, testículos y placenta. ${ }^{3}$ En el tejido adiposo se expresa, además de la ACE2, la enzima dipeptidil peptidasa 4 (DPP-4), que se ha identificado como receptor de MERS-CoV y que está incrementada en la diabetes y obesidad; participa favoreciendo el proceso inflamatorio al aumentar la actividad de los linfocitos $\mathrm{T}$ y la secreción de interleucinas. ${ }^{4}$

El consumo de tabaco, además de generar neumopatía crónica, aumenta significativamente la expresión génica de ACE2, convirtiéndose en factor de riesgo independiente para casos graves de COVID-19. ${ }^{5}$

Otra vía de entrada, que será explicada más adelante, es la participación de anticuerpos neutralizantes no eficientes, que se pudieron haber generado a partir de infecciones previas por otros coronavirus como SARS-CoV o, incluso, algunos betacoronoavirus implicados en el resfriado común. Este mecanismo se conoce como infección facilitada por anticuerpos o ADE (por sus siglas en inglés, antibody dependent enhancement). ${ }^{6}$ Figura 1 


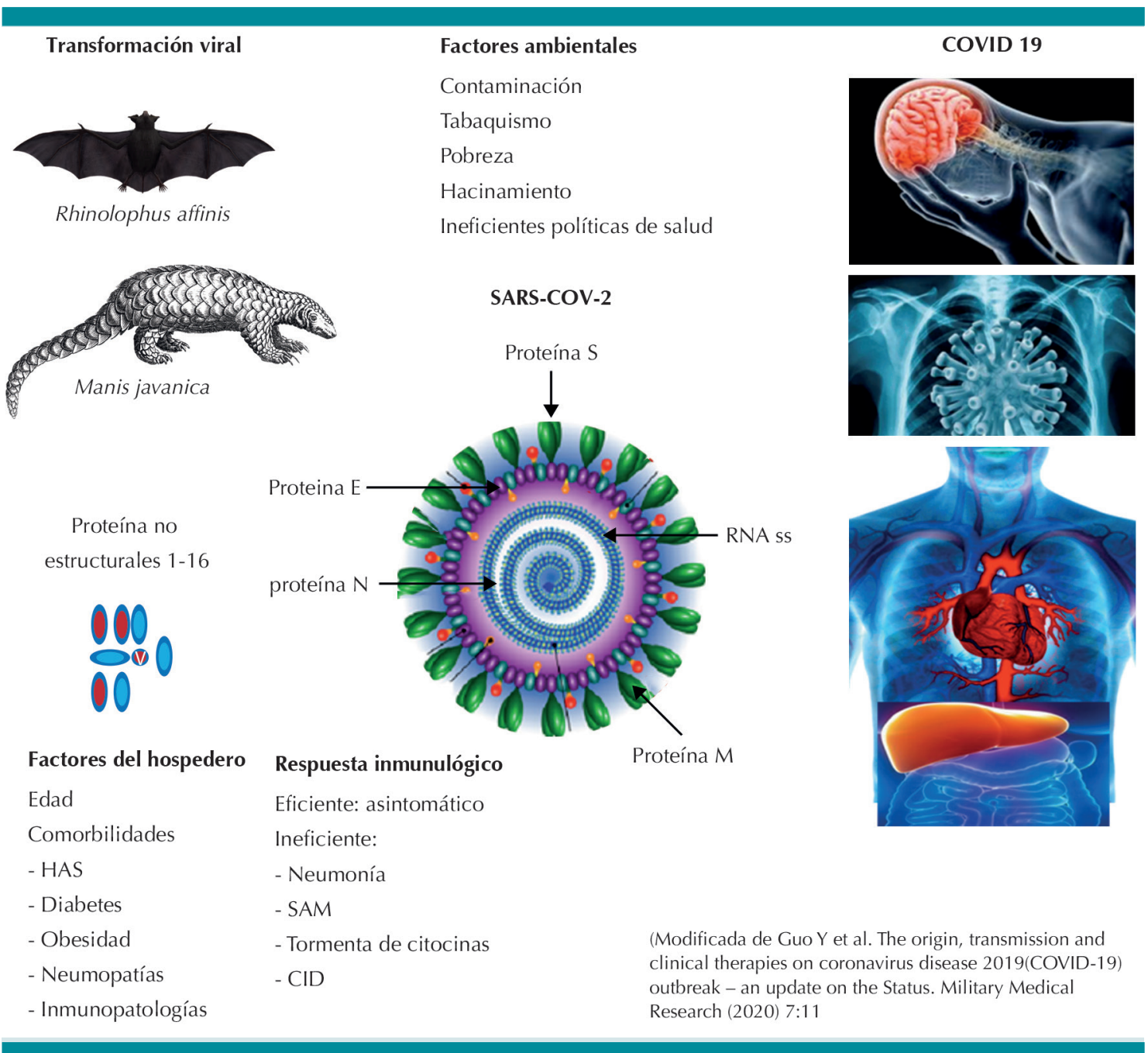

Figura 1. Factores virales y del huésped que influyen en la patogénesis del SARS-CoV2.

Los tratamientos con inhibidores de la ACE 2 y bloqueadores de los receptores de angiotensina II (enalapril, lisinopril, perindopril o losartán, valsartán entre otros) pueden aumentar su expresión, aunque no hay recomendación para suspender su consumo en los pacientes que ya lo hacían antes de la pandemia. ${ }^{\text {? }}$

ACE 2 varía su expresión según la edad: es mayor en los adolescentes de 17 años que en niños pequeños. Además, se expresa más en el género masculino. Se considera, entonces, que el estradiol y la testosterona pueden influir de manera diversa en la actividad de ACE. Esto explica la afectación del SARS-CoV y SARS-CoV-2 en ciertos grupos poblacionales. COVID-19 ha mostrado una diferencia en la tasa de mortalidad entre hombres $(2.8 \%)$ y mujeres $(1.7 \%) .8$

La afinidad en la unión de la proteína S y ACE2 es 10 a 20 veces mayor en SARS-CoV-2 que la observada con SARS-CoV, por lo que lo hace muy infectante. 
Los efectos farmacológicos que provoca la interacción de SARS-CoV-2 y ACE2 están relacionados con la reducción de la función del sistema renina-angiotensina-aldosterona (RAS) que influye en la presión sanguínea y equilibrio hidroelectrolítico, incrementando la permeabilidad vascular y la inflamación de las vías aéreas. ${ }^{10}$

Para comprender las características que encierran las manifestaciones clínicas sustentadas en el daño tisular en diversos órganos y sistemas de los pacientes es fundamental conocer las condiciones de la respuesta inmunológica ante la infección por SARS-CoV-2.

\section{Respuesta primaria a la infección por SARS-CoV-2}

Luego que el virus entra a la célula, el ácido ribonucleico (ARN) genómico funciona como lo hace un patrón molecular asociado a patógeno (PAMPs) que interactúa con receptores de reconocimiento de patrones (RRPs) de los que destacan los receptores tipo Toll (TLR3 y TLR7), el RIG-I-MDA5 (gen I inducible por ácido retinoico-proteína asociada a diferenciación de melanoma), que conduce a la activación de la cascada de señalización protagonizada por NF-кB (factor nuclear potenciador de las cadenas ligeras kappa de las células B activadas) e IRF3 (factor regulador de interferón 3). En los núcleos, estos factores de transcripción inducen la expresión de IFN (interferón) tipo I y otras citosinas proinflamatorias. Estas respuestas iniciales comprenden la primera línea de defensa contra la infección viral en el sitio de entrada. El interferón no solo actúa para controlar las infecciones virales, sino también para programar la respuesta inmunitaria adaptativa. ${ }^{11,12}$

EI SARS-CoV-2 tiene la característica de inducir respuestas aberrantes del interferón, principal- mente tardías, que ocasionan la pérdida de control viral en fase temprana de la infección de hasta 48 h. ${ }^{13}$

La célula huésped sufre piroptosis, que es un tipo de muerte celular programada, que se ve comúnmente con los virus citopáticos en donde la activación de la caspasa 1 genera la liberación de patrones moleculares asociados con daño, incluidos ATP, ácidos nucleicos y ASC (oligómeros de proteína adaptadora tipo speck asociada a apoptosis con dominio (ARD). A su vez, estos son reconocidos por las células epiteliales vecinas, células endoteliales y macrófagos alveolares, lo que desencadena la generación de citocinas y quimiocinas proinflamatorias (incluidas IL-6, IP-10, proteína inflamatoria de macrófagos $1 \alpha$ (MIP1 $\alpha)$, MIP1 $\beta$ y MCP1). Estas proteínas atraen monocitos, macrófagos y células T al sitio de la infección, promoviendo mayor inflamación (con la adición de IFN $\gamma$ producido por las células T) y estableciendo un circuito de retroalimentación proinflamatoria que, eventualmente, daña la infraestructura pulmonar. La tormenta de citocinas resultante circula a otros órganos, provocando daño múltiple. ${ }^{14,15}$ (Figura 2) El reclutamiento pulmonar de células inmunes de la sangre y la infiltración de linfocitos en las vías respiratorias que pueden explicar la linfopenia y el aumento de la relación neutrófilos-linfocitos observados en alrededor de $80 \%$ de los pacientes con infección por SARS-CoV-2. ${ }^{16}$

Las personas mayores de 60 años, y quienes padecen comorbilidades, tienen más probabilidades de tener una respuesta inmune tan disfuncional debido a un microambiente pulmonar envejecido, que altera la maduración de las células dendríticas ${ }^{17}$ y activación defectuosa de células T. En contraste, los niños tienden a no padecer enfermedad grave, a pesar de ser capaces 


\section{VIA AÉREA}

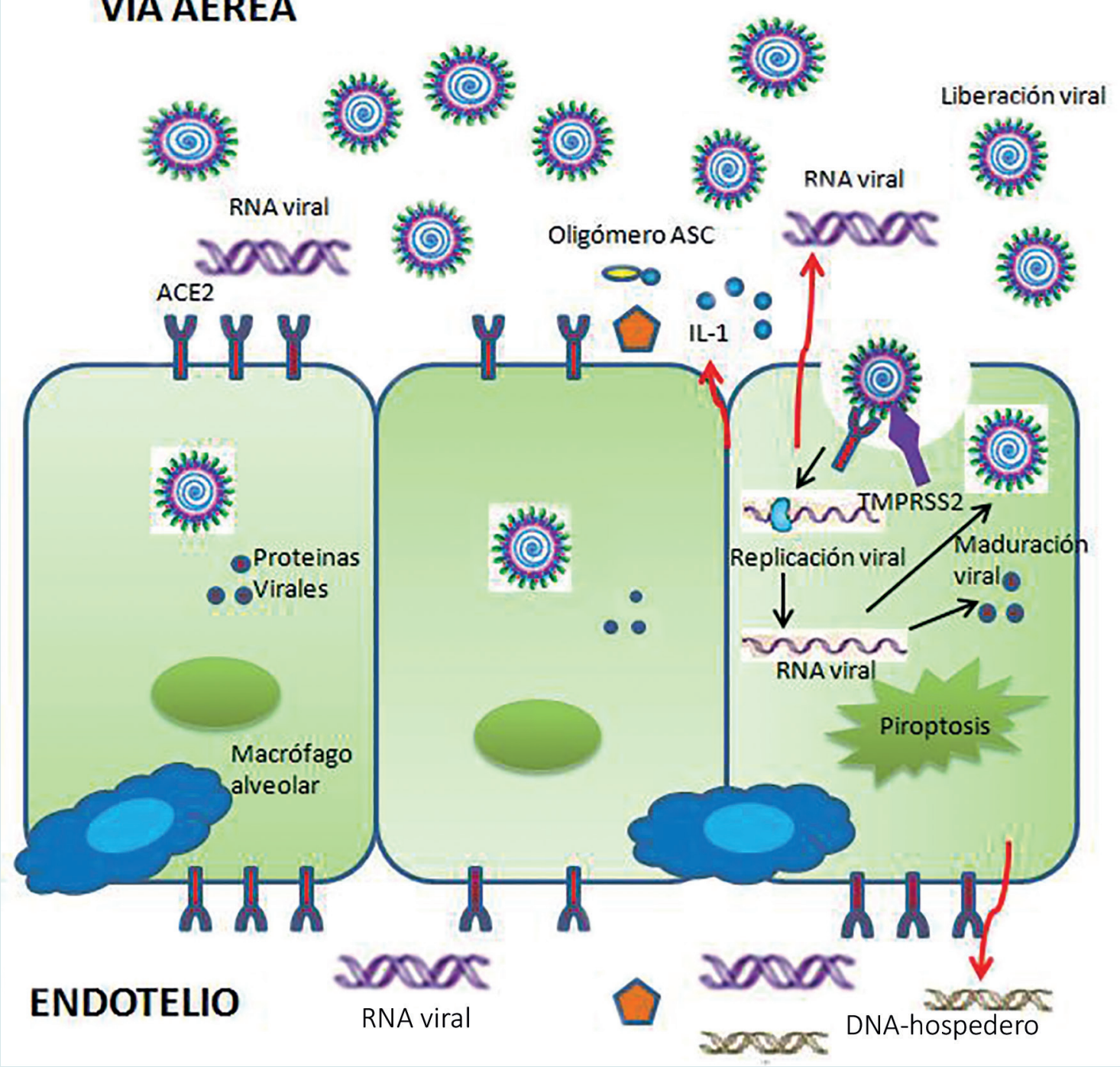

Figura 2. Cronología de eventos durante la infección por SARS-CoV-2.

Modificada de Tay, M.Z., Poh, C.M., Rénia, L. et al. The trinity of COVID-19: immunity, inflammation and intervention. Nat Rev Immunol (2020). https://doi.org/10.1038/s41577-020-0311-8

de experimentar títulos virales altos. ${ }^{18}$ En todos los grupos de edad menores de 18 años, más de $50 \%$ de los niños experimentaron síntomas leves o fueron asintomáticos, y menos de $6 \%$ de los niños tuvieron síntomas graves. ${ }^{19}$
Respuesta adaptativa a la infección por SARS-CoV-2

Es probable que, al Igual que SARS CoV, el SARS-CoV-2 infecte linfocitos $T$, macrófagos y 
células dendríticas derivadas de monocitos. La destrucción directa de los linfocitos por el virus podría contribuir a la linfopenia observada en pacientes. ${ }^{20-22}$

Los linfocitos T CD4 + y T CD8 + en particular, juegan un papel antiviral significativo al equilibrar el combate contra los patógenos con riesgo de autoinmunidad o inflamación abrumadora. Los T CD4 + promueven la producción de anticuerpos específicos de virus mediante la activación de células B, T-dependientes. Los linfocitos T CD8 + son citotóxicos y pueden matar a las células infectadas por virus; estos representan, aproximadamente, $80 \%$ del total de células infiltrativas en el intersticio pulmonar y desempeñan un papel vital en la eliminación de coronavirus en las células infectadas, induciendo lesiones inmunológicas graves. ${ }^{23-25}$

Las células T cooperadoras producen citocinas proinflamatorias a través de la vía de señalización del factor NF-kB; así, las citocinas IL-17 reclutan monocitos y neutrófilos al sitio de infección con inflamación y activación de cascadas de citocinas y quimiocinas posteriores, como IL-1, IL-6, IL-8, IL-21, TNF- $\beta$ y MCP- 1 . De memoria en SARS-CoV puede persistir hasta por 11 años después de la infección. ${ }^{26,27,28}$

\section{Participación de los anticuerpos en la infección por SARS-CoV-2}

En un estudio efectuado en 173 pacientes con infección por SARS-CoV-2 se observó que la tasa de seroconversión y las concentraciones de anticuerpos aumentaron rápidamente durante las primeras dos semanas, la tasa de seropositividad acumulada alcanzó 50\% en el día 11 y $100 \%$ en el día 39. El tiempo de seroconversión de los anticuerpos totales, IgM e IgG apareció, consecuentemente, $(p<0.05)$ con una media de un día de seroconversión a los 11, 12 y 14 días, respectivamente. ${ }^{29}$

En otro estudio llevado a cabo durante esta pandemia se evaluaron las concentraciones de IgM e IgG y se encontró que de 34 pacientes hospitalizados durante la semana 3 después del inicio de los síntomas, todos los pacientes dieron positivo para IgM e lgG; en la semana 4, todos los reportes fueron positivos para $\lg \mathrm{M}$ e $\lg \mathrm{G}$, aunque la IgM disminuyó mientras que la lgG continuó subiendo. En la semana 5, sin embargo, todos los pacientes resultaron positivos para IgG, mientras que 2 pacientes obtuvieron reportes negativos para IgM. Las concentraciones de IgM siguieron bajando y las de IgG continuaron subiendo hasta el final de las 7 semanas, donde 2 pacientes obtuvieron resultados negativos para IgM. ${ }^{30}$

Puesto que existen anticuerpos antivirales neutralizantes poco eficaces, ellos pueden facilitar la entrada del virus a las células huésped y conducir a mayor infectividad, mecanismo conocido como ADE (Antibody Dependent Enhancement) o facilitación de la infección por anticuerpos. Las cepas previamente infectantes pudieron ser coronavirus humanos causantes de resfriado común (229E) o varias cepas de coronavirus de murciélago o por SARS-CoV que comparte, aproximadamente, $79 \%$ de homología. ${ }^{31,32}$

\section{Síndrome de liberación o tormenta de citocinas en el síndrome de activación de macrófago} (SAM) secundaria a la infección por SARS-CoV-2

El SARS-CoV-2 es un tipo de virus citopático que induce lesiones y muerte celular y de tejidos como parte de su ciclo replicativo. Causa alta actividad de piroptosis con fuga vascular asociada. ${ }^{14,33}$

EL síndrome de activación de macrófago, también Ilamado linfohistiocitosis hemofagocítica 
secundaria (sHLH), es un síndrome inflamatorio poco reconocido que se caracteriza por una hipercitocinemia fulminante y mortal con insuficiencia multiorgánica. Se desencadena con mayor frecuencia por infecciones virales y ocurre en 3.7 a $4.3 \%$ de los casos con septicemia. Se caracteriza por fiebre constante, citopenias e hiperferritinemia. La afectación pulmonar (incluido el síndrome de dificultad respiratoria aguda o SDRA) ocurre, aproximadamente, en $50 \%$, conduce a edema pulmonar y daños en el hígado, corazón y riñones. Estos síntomas se asocian con la tormenta de citocinas. ${ }^{34}$

Los pacientes con COVID-19 grave, que requieren cuidados intensivos en hospitales, tienen concentraciones plasmáticas más altas de IL-2, IL-7, IL-10, factor estimulante de colonias de granulocitos (G-CSF), IP-10, MCP1, proteína inflamatoria de macrófagos $1 \alpha$ (MIP1 $\alpha$ ) y factor de necrosis tumoral (TNF).

La elevación sostenida de IL-6 e IL-1, además proteína $\mathrm{C}$ reactiva (PCR) muy elevada e hiperferritinemia, es decisiva para el diagnóstico de SAM/HLH. ${ }^{27,28}$ La IL- 6 puede generar este proceso a través de dos vías de señalización conocidas como cis o clásica y una trans. En la vía cis la IL-6 se une al receptor de IL-6 de la membrana (mIL-6R) en un complejo gp130. La transducción de señal posterior está mediada por JAK (Janus cinasas) y STAT3 (transductor de señal y activador de la transcripción 3). La activación de la señalización cis produce efectos pleiotrópicos en el sistema inmunitario adquirido (células B y T) y en el sistema inmunitario innato [neutrófilos, macrófagos y células asesinas naturales (NK)], que pueden contribuir a la tormenta de citocinas. ${ }^{35} \mathrm{En}$ la señalización trans, las altas concentraciones circulantes de IL-6 se unen a la forma soluble de IL-6R (sIL-6R). La señalización resultante de IL-6-SIL-6R-JAK-STAT3 se activa en células que no expresan mIL-6R, como las células endoteliales. Esto da como resultado una "tormenta de citocinas" sistémica que implica la secreción del factor de crecimiento endotelial vascular (VEGF), proteína quimioatrayente de monocitos -1 (MCP1), IL-8 e IL-6 adicional, así como una expresión reducida de E-cadherina en células endoteliales. El factor de crecimiento endotelial vascular y la expresión reducida de E-cadherina contribuyen a la permeabilidad vascular y la fuga, que participan en la fisiopatología de la hipotensión y la disfunción pulmonar en el síndrome de dificultad respiratoria aguda. ${ }^{36}$ Figura 3

La participación de células TH17 y TH1 que expresan TNF $\alpha$ y producen IL-17 tiene amplios efectos proinflamatorios porque inducen: a) producción de citocinas responsables de la granulopoyesis y el reclutamiento de neutrófilos o factor estimulante de colonias de granulocitos (G-CSF), IL-1 $\beta$, IL-6, TNF $\alpha$ (causan síntomas inflamatorios sistémicos, incluida la fiebre); $b$ ) quimiocinas KC, MIP2A, IL-8, IP10, MIP3A (atrayendo y reclutando infiltrados inmunes); $y$ c) metaloproteinasas de matriz (que participan en el daño tisular y la remodelación). ${ }^{26,37}$

En los pacientes infectados, acompañando a la respuesta descontrolada de macrófagos, hay una activación patológica de la trombina; por ello se observan múltiples episodios trombóticos que van desde isquemia periférica, tromboembolismo pulmonar hasta coagulación intravascular diseminada (CID). ${ }^{38}$ Podría estar asociada con una microtrombosis pulmonar extensa en lugar de la CID que, generalmente, ocurre con el síndrome de activación de macrófago activado (SAM). ${ }^{39}$

\section{Mucosa oral en la infección por COVID-19}

Las células del epitelio de las glándulas salivales tienen alta expresión de ACE2, aún con más 


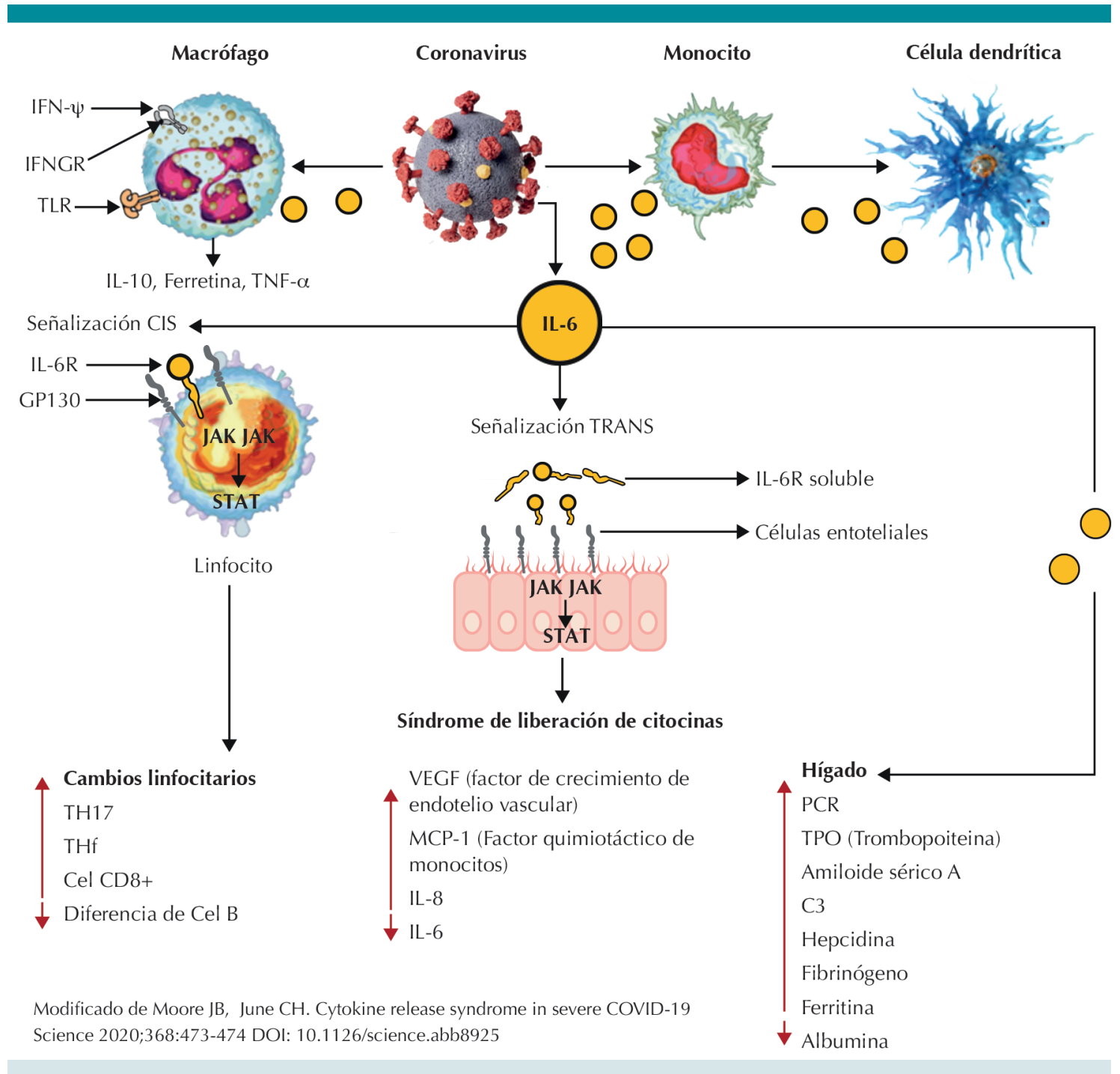

Figura 3. Vías de activación del síndrome de liberación de citocinas.

expresión que epitelio pulmonar. ${ }^{44} \mathrm{El}$ ARN en SARS-CoV puede detectarse en la saliva antes de que aparezcan las lesiones pulmonares. La tasa positiva de COVID-19 en la saliva de los pacientes puede alcanzar $91.7 \%{ }^{40}$

\section{Patología pulmonar}

De acuerdo con la progresión del síndrome de dificultad respiratoria aguda, los blancos principales de la infección por SARS-CoV-2 son las células ciliadas del epitelio de las vías respiratorias. Los neumocitos alveolares de tipo II $^{41}$ muestran una respuesta inflamatoria inespecífica que juega un papel importante a lo largo del curso de la enfermedad. Se caracteriza por edema e infiltración celular; también exfoliación severa de células epiteliales alveolares, ensanchamiento septal alveolar, infiltración e hiperplasia, daño a las paredes arteriolares 
intersticiales pulmonares, daño a tabiques alveolares e infiltración organizada del espacio alveolar, formación de membrana hialina y finalmente necrosis. ${ }^{42}$ Limita la eficiencia del intercambio de gases en el pulmón, causa dificultad para respirar y bajas concentraciones de oxígeno en la sangre. Así mismo, el pulmón se vuelve más vulnerable a las infecciones se-

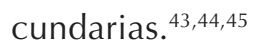

Puede suceder una lesión pulmonar aguda a través de la enzima convertidora de angiotensina (ACE) que convierte la angiotensina I (AT I) en angiotensina II (AT II), se produce cuando AT II se une al receptor $1 \mathrm{a}$ de angiotensina II (AT1 $\mathrm{aR}$ ) provocando daño tisular y edema pulmonar. ${ }^{46}$

\section{Daño al tubo digestivo y al hígado}

ACE2 no solo tiene una alta expresión en las células AT2 pulmonares, sino también en células epiteliales superiores y estratificadas del esófago y enterocitos absorbentes del íleon y el colon. Con el aumento de la permeabilidad de la pared gastrointestinal a los patógenos extraños, una vez infectados por el virus, la malabsorción de enterocitos invadidos produce síntomas entéricos como diarrea, lo que en teoría indica que el sistema digestivo podría ser vulnerable a la infección por COVID-19. ${ }^{47}$

En 73 pacientes hospitalizados, 39 (53.24\%); 25 hombres y 14 mujeres se encontró ácido ribonucleico viral en las muestras fecales, presentes en 1 a 12 días. Diecisiete (23.19\%) siguieron teniendo ácido ribonucleico viral en las muestras fecales después de que los síntomas respiratorios habían mejorado. ${ }^{48}$

Entre 2 y $10 \%$ de los pacientes con COVID-19 suelen tener diarrea; en ellos se ha detectado ARN del SARS-CoV-2 en muestras de heces y sangre. ${ }^{49}$ Esta evidencia implica la posibilidad de exposición viral en el hígado; se ha encontrado expresión del receptor ACE2 en colangiocitos, ${ }^{50}$ indicativa de SARS-CoV-2. El análisis patológico del tejido hepático de un paciente que murió por COVID-19 mostró que no se observaron inclusiones virales en el hígado. ${ }^{51}$ La gamma-glutamil transferasa (GGT), un biomarcador de diagnóstico para la lesión de colangiocitos, estaba elevada en 30 (54\%) de 56 pacientes con COVID-19. También se observaron concentraciones elevadas de fosfatasa alcalina en un paciente. Puesto que la expresión del receptor ACE2 en los colangiocitos puede agravar la colestasis en pacientes con colangitis biliar primaria con aumento de la fosfatasa alcalina y GGT, los pacientes con cirrosis hepática o cáncer de hígado podrían resultar más susceptibles a la infección por SARS-CoV-2 debido a su estado inmunodeficiencia sistémica. Por esto deben evaluarse, con todo cuidado, las enfermedades hepáticas preexistentes, incluidas la hepatitis viral crónica, la enfermedad del hígado graso no alcohólico y la enfermedad hepática relacionada con el alcohol. Es difícil diferenciar si el incremento de las concentraciones de las enzimas hepáticas es consecuencia de la acción del virus o de un daño hepático inducido por fármacos hepatotóxicos, como las estatinas, remdesivir y tocilizumab. ${ }^{47,52}$

\section{Enfermedad cardiovascular}

Más de 7.5\% de las células miocárdicas tienen una expresión positiva de ACE2. La lesión cardiaca se caracteriza por: síndrome coronario agudo debido a rotura de placa o trombosis (infarto de miocardio tipo I (IM)) o desajuste de la oferta y la demanda (IM tipo II), lesión miocárdica debida a coagulación intravascular diseminada y lesión no isquémica (miocarditis, miocardiopatía inducida por estrés o síndrome de liberación de citocinas). 
Los hallazgos patológicos varían desde cambios mínimos hasta infiltración inflamatoria intersticial y necrosis miocítica. En la vasculatura puede encontrarse microtrombosis e inflamación vascular.

SARS-CoV-2 puede provocar la liberación intensa de múltiples citocinas y quimiocinas por el sistema inmunitario. La IL -1 , IL-6, IFN- $\gamma$ y $\mathrm{TNF}-\alpha$, las citocinas proinflamatorias deprimen la función miocárdica inmediatamente a través de la activación de la vía de la esfingomielinasa neural y de manera subaguda (horas a días) a través de la reducción mediada por óxido nítrico de la señalización betaadrenérgica.

La elevación de la troponina cardiaca de alta sensibilidad (hs-cTn) por encima del percentil 99 de su límite superior de la normalidad se asocia con mortalidad hospitalaria en $7.6 \%$ de los pacientes sin enfermedad cardiovascular subyacente y troponina normal, $13.3 \%$ para quienes tienen enfermedad cardiovascular $y$ troponina normal, $37.5 \%$ para quienes no tienen enfermedad cardiovascular pero troponina elevada y $69.4 \%$ para aquellos con enfermedad cardiovascular y troponina elevada. También se observó que los pacientes con troponina elevada tuvieron mayor incidencia de arritmia maligna (taquicardia ventricular hemodinámicamente inestable o fibrilación ventricular) que quienes tuvieron concentraciones normales de troponina (11.5 vs $5.2 \%, \mathrm{p}<0.001$ ).

La prevalencia de trombosis venosa profunda confirmada por ultrasonido en pacientes con Covid-19 es de $22.7 \%$ y de $27 \%$ en pacientes internados en cuidados intensivos.

El dímero D mayor de $1 \mu \mathrm{g} / \mathrm{mL}$ al ingreso se asoció con muerte en el hospital (OR: 18.4, IC95\%: 2.6-128.6; $p=0.003)$. La coagulación intravascular diseminada fue una afección po- tencialmente mortal coexistente en 15 de 21 pacientes que no supervivieron a la COVID-19 y 1 de 162 de los supervivientes y se ha asociado con trombosis de las arterias coronarias (vasos epicárdicos y microvasculatura), necrosis focal del miocardio y disfunción cardiaca severa. ${ }^{53,54,55}$

\section{Nefropatía por el virus SARS-CoV-2}

En estudios con virus similares al COVID-19, los pacientes renales crónicos resultaron más susceptibles a las complicaciones graves por la infección viral: neumonías con cuadro de insuficiencia respiratoria aguda y lesiones renales agudas. Los podocitos y túbulos proximales renales expresan ACE2. El daño renal se caracteriza por proteinuria $(63 \%)$, en ocasiones en el rango nefrótico (34\%), hematuria (20\%) e incremento de los productos nitrogenados (27\%) y la creatinina $(19 \%)$ y se consideran factor de riesgo en la mortalidad. ${ }^{56,57}$ La lesión renal aguda se origina por la sobreproducción de citocinas, rabdomiolisis, sepsis y el daño directo del virus a las células de los túbulos renales. Se observa en 5.1 y $27 \%$ de los casos y empeora el pronóstico de la enfermedad. Algunos de los medicamentos indicados para tratar la COVID-19 pueden, eventualmente, ser nefrotóxicos. ${ }^{58}$ En el aspecto anatomopatológico se observó infiltrado linfocitario en el intersticio renal y necrosis tubular. Las tinciones de inmunohistoquímica revelaron, in situ, la acumulación del antígeno viral SARSCoV-NP en los túbulos renales. ${ }^{59}$ En los pacientes en diálisis y trasplantados es necesario tomar medidas de prevención porque su condición inmunológica los predispone a las complicaciones graves.

\section{Afectación neurológica}

Las manifestaciones clínicas relacionadas con el sistema nervioso, que van desde la cefalea 
hasta síncopes, crisis anóxicas e ictus, pueden explicarse, en principio, por la hipoxia, por un metabolismo anaeróbico en las células del sistema nervioso central, así como la formación de edema celular e intersticial, isquemia y vasodilatación en la circulación cerebral. ${ }^{60}$ La respuesta inmunitaria por parte del huésped también puede tener algún papel. Los coronavirus son capaces de infectar a los macrófagos, astroglía y microglía; las células gliales son capaces de secretar factores proinflamatorios, IL-6, IL-12, IL-15 y TNF alfa. ${ }^{61}$ La rutas de propagación al sistema nervioso central pueden ser por vía hematógena o linfática, y por diseminación retrógrada desde las terminales nerviosas periféricas.

Esta última se lleva a cabo en la lámina cribiforme del etmoides y desde pulmón a través de los mecanorreceptores y quimiorreceptores localizados en el mismo y que causan la muerte por disfunción secundaria de los centros de control cardiorrespiratorios del bulbo raquídeo. ${ }^{62} \mathrm{El}$ SARS-CoV2, en busca de su receptor ACE2, puede llegar a las células endoteliales e interactuar con el endotelio capilar y replicarse en su interior y propagarse a las neuronas. ${ }^{63-64}$ Los trastornos del olfato y del gusto pueden observarse en 85.6 vs $88 \%$ de los pacientes. ${ }^{65}$ La encefalopatía es un síndrome de disfunción cerebral transitoria que se manifiesta como una afectación aguda o subaguda. La encefalitis es un diagnóstico diferencial de otros virus neurótropos, como la familia del herpes simple, de la varicela zóster o el virus del Nilo. ${ }^{66}$

La encefalopatía necrotizante aguda hemorrágica puede detectarse con la TAC cerebral, donde se observa un área hipodensa simétrica y bilateral en el núcleo talámico medial. La resonancia da lesiones hemorrágicas que se realzan después de la administración de contraste, de disposición multifocal y simétrica, en forma anular en ambos tálamos, la ínsula y la región medial de los lóbulos temporales. ${ }^{67}$ Las complicaciones cerebrovasculares son observadas en pacientes ancianos. En un estudio retrospectivo de 221 pacientes con COVID-19 de Wuhan, 11 (5\%) tuvieron ictus isquémico; $1(0.5 \%)$ trombosis cerebral de los senos venosos; y otro $(0.5 \%)$, una hemorragia cerebral. Los factores de riesgo de sufrir enfermedad cerebral aguda fueron: edad avanzada (edad media: 71.6 años), padecer COVID-19 grave, antecedentes de hipertensión, diabetes o enfermedad cerebrovascular, o respuesta inflamatoria y procoagulante marcada (aumento de la proteína $C$ reactiva y el dímero $D$, respectivamente). La mortalidad fue de $38 \%{ }^{68}$ Se ha observado, aisladamente, síndrome de Guillain-Barré. ${ }^{69} \mathrm{El}$ Cuadro 1 agrupa las principales complicaciones neurológicas observadas en COVID-19. ${ }^{70}$

\section{Afectación al metabolismo del grupo hemo de la hemoglobina}

Se ha considerado que el ORF8 y la glicoproteína de superficie podrían unirse a la porfirina, lo mismo que las proteínas orf1ab, ORF10 y ORF3a podrían coordinar el ataque del hem en la cadena 1-beta de la hemoglobina para disociar el hierro para formar la porfirina. La desoxihemoglobina es más vulnerable a los ataques de virus que la hemoglobina oxidada. El ataque causará cada vez menos hemoglobina que puede transportar oxígeno y dióxido de carbono, produciendo síntomas de dificultad respiratoria. Las células pulmonares tienen incapacidad de intercambiar dióxido de carbono y oxígeno con la consecuente inflamación que se traduce, finalmente, en imágenes pulmonares de vidrio esmerilado. Así, la cloroquina podría evitar que orf1ab, ORF3a y ORF10 ataquen el hem para formar la porfirina e inhiban la unión de ORF8 y las glucoproteínas de la superficie 
a las porfirinas, con el propósito de aliviar los síntomas de dificultad respiratoria. El favipiravir podría inhibir que la proteína de la envoltura y la proteína ORF7a se unan a la porfirina, evitar que el virus ingrese a las células huésped y atrapar las porfirinas libres. ${ }^{71}$

Cuadro I. Complicaciones neurológicas en COVID-1970

\begin{tabular}{|c|c|}
\hline \multirow[t]{3}{*}{$\begin{array}{l}\text { Infección del sistema } \\
\text { nervioso central }\end{array}$} & $\begin{array}{c}\text { Encefalitis/ } \\
\text { meningitis aguda }\end{array}$ \\
\hline & Encefalomielitis \\
\hline & Mielitis transversa aguda \\
\hline \multicolumn{2}{|c|}{ Síndromes (posiblemente) inmunomediados } \\
\hline & $\begin{array}{l}\text { Mononeuritis/afectación } \\
\text { de los pares craneales }\end{array}$ \\
\hline & $\begin{array}{l}\text { Síndrome de Guillain- } \\
\text { Barré y variantes } \\
\text { (Miller Fisher) }\end{array}$ \\
\hline & $\begin{array}{l}\text { Mielitis transversa } \\
\text { postinfecciosa }\end{array}$ \\
\hline & $\begin{array}{l}\text { Encefalomielitis aguda } \\
\text { diseminada }\end{array}$ \\
\hline & $\begin{array}{l}\text { Encefalomielitis } \\
\text { necrotizante }\end{array}$ \\
\hline & Cerebelitis aguda \\
\hline & $\begin{array}{l}\text { Parkinsonismo } \\
\text { postencefalítico }\end{array}$ \\
\hline & $\begin{array}{l}\text { Síndrome de fatiga } \\
\text { crónica post-COVID-19 }\end{array}$ \\
\hline \multicolumn{2}{|c|}{$\begin{array}{l}\text { Complicaciones neurológicas asociadas a } \\
\text { tormenta de citocinas }\end{array}$} \\
\hline \multirow[t]{3}{*}{$\begin{array}{l}\text { Complicaciones } \\
\text { cerebrovasculares }\end{array}$} & $\begin{array}{l}\text { Ataque isquémico } \\
\text { transitorio }\end{array}$ \\
\hline & Ictus isquémico \\
\hline & Ictus hemorrágico \\
\hline \multicolumn{2}{|c|}{ Complicaciones neuromusculares } \\
\hline & Mialgia \\
\hline & Rabdomiólisis \\
\hline $\begin{array}{l}\text { Complicaciones } \\
\text { neurooftalmológicas }\end{array}$ & \\
\hline
\end{tabular}

\section{CONCLUSIONES}

El conocimiento de la fisiopatogenia de cualquier enfermedad es, realmente, una obligación del médico porque ello le permite establecer un conjunto de razonamientos que facilitan crear una ruta crítica para resolver los casos con optimización de los recursos y seguridad para el paciente.

Las enfermedades infecciosas tienen una serie de características que, muchas veces, confunden al clínico y lo hacen tomar medidas muy distantes o, quizá, parciales para proporcionar solucionarlas. Por esto siempre deben contemplarse los elementos que integran un proceso infeccioso: participación evidente del agente que aporta elementos de virulencia y patogenicidad con los que agrede a su hospedero. El otro factor es el medio, que representa mucho de lo que condiciona que los individuos y poblaciones caigan, frecuentemente, en enfermedad. Un ejemplo muy evidente es la contaminación ambiental, entre otros. Por último, el hospedero que, gracias a sus mecanismos de protección que le proporcionan los integrantes de la respuesta inmunológica, le permiten resolver esa agresión que le ocasionan los agentes infecciosos. Por esto es decisivo conocer, en estas circunstancias, los componentes de la respuesta inmunológica con que nos encontramos defendiéndonos todos los integrantes de la humanidad contra el SARS-CoV-2.

Esta pandemia está proporcionando a la población en general y a los médicos en particular una visión diferente de las enfermedades infecciosas porque ha acelerado la identificación de procesos fisiopatogénicos con la finalidad de obtener, a la brevedad, recursos terapéuticos eficientes que mitiguen todo el estrago en la salud, economía y calidad de vida de la sociedad. Debemos estar comprometidos a permitir que los estragos que ocasiona este virus en los individuos con comorbilidades se detengan. Es necesario implementar, racionalmente, las terapias fármaco- 
inmunológicas que con evidencia aparezcan y sean accesibles; pero, sobre todo, debemos coadyuvar al inicio de cambios en las políticas de salud que impidan, sustancialmente, continuar con el deterioro tan grave de la salud de niños y adultos, como lo hemos estado comprobando.

\section{REFERENCIAS}

1. Haibo Zhang $\mathrm{H}$, et al. Angiotensin-converting enzyme 2(ACE2) as a SARS-CoV-2 receptor: molecular mechanisms and potential therapeutic target. Intensive Care Med 2020; 46: 586-90. https://doi.org/10.1007/s00134-020-05985-9

2. Guo $Y$ et al. The origin, transmission and clinical therapies on coronavirus disease 2019(COVID-19). outbreak - an update on the Status. Military Medical Research 2020; 7: 11. https:// doi.org/10.1186/s40779-020-00240-0)

3. Soler MJ, et al. Enzima conversiva de la angiotensina 2 y su papel emergente en la regulación del sistema reninaangiotensina. Med Clin (Barc) 2008;131(6): 230-36.

4. Malavazos A, et al. Targeting the adipose tissue in COVID 19. Obesity. doi: 10.1002 / oby. 22844

5. Cai G. Bulk and single-cell transcriptomics identify tobacco-use disparity in lung gene expression of ACE2, the receptor of 2019-nCov. Med Rxiv. 2020; doi:10.1101/2020.02.05.20020107 (preprint).

6. Wang JM, et al. the potential for antibody-dependent enhancement of SARS-CoV-2 Infection: Translational Implications for Vaccine Development. Journal of Clinical and Translational Science 2020. doi:10.1017/cts.2020.39

7. Watkins J. Preventingacovid-19 pandemics. BMJ 2020; 368. doi: https://doi.org/10.1136/bmj.m810

8. Landazuri $P$, et al. Diferencias entre los sexos en la actividad de la enzima conversora de la angiotensina y en la presión arterial en niños: un estudio observacional. Arq Bras Cardiol 2008; 91(6):.17-23.

9. Bouman, A, et al. Sex hormones and the immune response in humans. Human Reproduction Update 2005; 11(4), 41123. https://doi.org/10.1093/humupd/dmi008

10. Zhang $\mathrm{H}$, et al. Angiotensin converting enzyme 2 (ACE2) as a SARS-CoV2 receptor: molecular mechanisms and potential therapeutic target. Intensive Care Med 2020: 46: 586-90. https://doi.org/10.1007/s00134-020-05985-9

11. Channappanavar R, et al. T cell-mediated immune response to respiratory coronaviruses. Immunol Res. 2014; 59:118-28.

12. Cervantes B, et al. Type I IFN-mediated protection of macrophages and dendritic cells secures control of murine coronavirus infection. J Immunol. 2009; 182: 1099-106.

13. Cameron MJ, et al. Interferon-mediated immunopathological events are associated with atypical innate and adaptive immune responses in patients with severe acute respiratory syndrome. J Virol. 2007; 81: 8692-706.
14. Fink SL, et al. Apoptosis, pyroptosis, and necrosis: mechanistic description of dead and dying eukaryotic cells. Infect Immun. 2005; 73: 1907-16.

15. Mali SN, et al. The rise of new coronavirus infection (COVID-19): A recent update and potential therapeutic candidates. EJMO. 2020; 4 (1):35-41.

16. $\mathrm{Xu} \mathrm{Z}$, et al. Pathological findings of COVID-19 associated with acute respiratory distress syndrome. Lancet Respir Medicin. 2020; 8 :420-22. https://doi.org/10.1016/ S2213-2600(20)30076-X

17. Bonanad C, et al. Coronavirus: the geriatric emergency of 2020. Joint document of the Section on Geriatric Cardiology of the Spanish Society of Cardiology and the Spanish Society of Geriatrics and Gerontology. Rev Esp Cardiol (English Edition (2020). https://doi.org/10.1016/j. rec.2020.05.001

18. Kam KQ-, et al. A well infant with coronavirus disease 2019 (COVID-19) with high viral load. -Clin Infect Dis. 2020;ciaa201. doi:10.1093/cid/ciaa201

19. Dong $Y$, et al. Epidemiological characteristics of 2143 pediatric patients with 2019 coronavirus disease in China. Pediatrics 2020 Mar 16. pii: e20200702. doi: 10.1542/ peds.2020-0702.

20. Gu J, et al. Multiple organ infection and the pathogenesis of SARS. J Exp Medicin. 2005; 202: 415-24.

21. Cheung $\mathrm{CY}$, et al. Cytokine responses in severe acute respiratory syndrome coronavirus-infected macrophages in vitro: Possible relevance to pathogenesis. J Virol. 2005; 79 : 7819-26. DOI: 10.1128/JVI.79.12.7819-7826.2005

22. Yilla $M$, et al. SARS-coronavirus replication in human peripheral monocytes-macrophages. Virus Res. 2005; 107: 93-101.

23. Faraha GA, et al. Increased expression of CD8 marker on T-cells in COVID-19 patients. Blood Cells Mol Dis. 2020; 83:102437. doi: 10.1016/j.bcmd.2020.102437.

24. García-Salido A. Revisión narrativa sobre la respuesta inmunitaria frente a coronavirus: descripción general, aplicabilidad para Sars-Cov2 e implicaciones terapéuticas. Anales de Pediatría (2020). https://doi.org/10.1016/j. anpedi.2020.04.

25. Geng Li, et al. Coronavirus infections and immune responses. J Med Virol. 2020; 92:424-32. https://doi. org/10.1002/jmv.25685

26. Wu D, et al. TH17 responses in cytokine storm of COVID-19: An emerging target of JAK2 inhibitor Fedratinib. Journal of Microbiology, Immunology and Infection. https://doi. org/10.1016/j.jmii.2020.03.005

27. Maloir $Q$, et al. Acute respiratory distress revealing antisynthetase syndrome. Rev Med Liege. 2018; 73(7-8): 370-75.

28. Ow Ng, et al. Memory $\mathrm{T}$ cell responses targeting the SARS coronavirus persist up to 11 years post-infection. Vaccine. 2016; 34(17):2008-2014.

29. Zhao J, et al. Antibody responses to SARS-CoV-2 in patients of novel coronavirus disease 2019, Clinical Infectious Diseases. 2020, ciaa344. https://doi.org/10.1093/cid/ciaa344 
30. Xiao T, et al. Profile of specific antibodies to SARS-CoV-2: The First Report. J Infection 2020. doi: https://doi. org/10.1016/j.jinf.2020.03.012)

31. Ho MS, et al. Neutralizing Antibody Response and SARS Severity. Emerg Infect Dis. 2005; 11: 1730-37.

32. Lu R, et al. Genomic characterization and epidemiology of 2019 novel coronavirus: implications for virus origins and receptor binding. Lancet 2020; 20:30251-58. pii: S0140-6736.

33. Chen IY, et al. Severe acute respiratory syndrome coronavirus Viroporin 3a Activates the NLRP3 Inflammasome. Front Microbiol. 2019;10: 50. doi: 10.3389/fmicb.2019.00050. eCollection 2019.

34. Metha $P$, et al. COVID-19: consider cytokine storm syndromes and immunosuppression. Lancet. 2010; 395: 103334. https://doi.org/10.1016/ S0140-6736(20)30630-9

35. Chan JF, et al. A familial cluster of pneumonia associated with the 2019 novel coronavirus indicating person-toperson transmission: a study of a family cluster Lancet. 2020; 395: 514-23.

36. Moore JB, et al. Cytokine release syndrome in severe COVID-19 Science 2020;368:473-474 DOI: 10.1126/science.abb8925

37. Pacha O, et al. COVID-19: a case for inhibiting IL-17?. Nat Rev Immunol (2020). https://doi.org/10.1038/s41577020-0328-z

38. Respuesta inmune trombótica asociada a COVID-19 Modificado de (RITAC) Gauna M https://fundacionio.com/ wp-content/uploads/2020/04/Si\%CC\%81ndrome RITAC. pdf.pdf.pdf.pdf.pdf.pdf.pdf

39. McGonagle D, et al. Interleukin-6 use in COVID-19 pneumonia related macrophage activation syndrome Autoimmunity Reviews 2020. https://doi.org/10.1016/j. autrev.2020.102537

40. Wang WK, et al. Detection of SARS-associated coronavirus in throat wash and saliva in early diagnosis. Emerg Infect Dis. 2004;10 (7): 1213-19.

41. Sims AC, et al. Severe acute respiratory syndrome coronavirus infection of human ciliated airway epithelia: Role of ciliated cells in viral spread in the conducting airways of the lungs. J Virol. 2005; 79: 155111-24.

42. Ling Lin, et al. Hypothesis for potential pathogenesis of SARS-CoV-2 infection-a review of immune changes in patients with viral pneumonia. Emerging Microbes \& Infections 2020; 9: 727-32. doi: 10.1080/22221751.2020.1746199

43. Zhou F, et al. Clinical course and risk factors for mortality of adult inpatients with COVID-19 in Wuhan, China: a retrospective cohort Study. Lancet 2020; 395: 1054-62.

44. Liao $\mathrm{M}$, et al. The landscape of lung bronchoalveolar immune cells in COVID-19 revealed by single-cell RNA sequencing. Preimpression en medRxiv 2020. https://doi. org/10.1101/2020.02.23.20026690.
45. Zhou $Y$, et al. Pathogenic $T$ cells and inflammatory monocytes incite inflammatory storm in severe COVID-19 patients. Natl Sci Rev 2020. https://doi.org/10.1093/nsr/ nwaa041.

46. Carolyn M, et al. MD1 Viral Pathogens and Acute Lung Injury: Investigations Inspired by the SARS Epidemic and the 2009 H1N1 Influenza. Semin Respir Crit Care Med. 2013; 34:475-86.

47. Gu J, et al. COVID-19: COVID-19: Gastrointestinal Manifestations and Potential Fecal-Oral Transmission. Gastroenterology 2020 Mar 3. doi: 10.1053/j.gastro.2020.02.054.

48. Xiao $F$, et al. Evidence for gastrointestinal infection of SARS-CoV-2. Gastroenterology. 3 Mar 2020: S00165085(20)30282-1. doi: 10.1053/j.gastro.2020.02.055. PMID: 3214277.

49. Yeo $\mathrm{C}$, et al. Enteric involvement of coronaviruses: is faecal-oral transmission of SARS CoV-2 possible? Lancet Gastroenterol Hepatol. 2020. doi: 10.1016/S24681253(20)30048-0. published online Feb 19

50. Chai $X$, et al. Specific ACE2 expression in cholangiocytes may cause liver damage after 2019-nCoV infection. bioRxiv. 2020 doi: 10.1101/2020.02.03.931766. published online Feb 4. (preprint)

51. Xu Z, et al. Pathological findings of COVID-19 associated with acute respiratory distress syndrome. Lancet Respir Med. 2020 doi: 10.1016/S2213-2600(20)30076-X. published online

52. Zhang C, Shi L, Wang FS. Liver injury in COVID-19: Management and challenges. Lancet Gastroenterol Hepatol 2020 Mar 4. doi: 10.1016/S2468-1253(20)30057-1.

53. Kang $Y$, Chen $T$,Mui $D$, et al. Heart Epub ahead of print: [please include Day Month Year]. doi:10.1136/heartjnl-2020-317056

54. Guo T, Fan $\mathrm{Y}, \mathrm{Chen} \mathrm{M}$, et al. Cardiovascular implications of fatal outcomes of patients with coronavirus disease 2019 (COVID-19). JAMA Cardiol 2020.

55. Sugiura M, Hiraoka K, Ohkawa S, et al. A clinicopathological study on cardiac lesions in 64 cases of disseminated intravascular coagulation. Jpn Heart J. 1977; 18:57-69.

56. Xu D, et al. Identification of a Potential Mechanism of Acute Kidney Injury During theCOVID-19 Outbreak: A Study Bas don Single Cell Transcriptome Analysis Preprints 2020 2020020331

57. Cheng $\mathrm{Y}$, et al. Kidney impairment is associated with inhospital death of COVID-1 patients med Rxiv. 2020 https://doi. org/10.1101/2020.02.18.20023242.

58. Wang $T$, et al. Comorbidities and multi-organ injuries in the treatment of COVID-19. Lancet 2020; 395:10228. https:// doi.org/101016/S0140- 6736(20)30558-4

59. Diao B, et al. Human kidney is a target for novel severe acute respiratory syndrome coronavirus 2 (SARS-Cov-2) infection medRxiv 2020 Doi: https://doi. org/10.1101/2020.03.04.20031120 
López-Pérez GT, et al. Fisiopatología de la infección por virus SARS-CoV-2

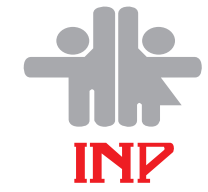

60. Wu Y, et al. Nervous system involvement after infection with COVID-19 and other coronaviruses. Brain Behav Immun 2020; Mar 30. [Epub ahead of print].

61. Bohmwald K, et al. Neurologic alterations due to respiratory virus infections. Front Cell Neurosci. 2018; 12: 386.

62. Li Y, et al. Acute cerebrovascular disease following COVID-19: a single, retrospective, observational study. Lancet 2020. http://dx.doi.org/10.2139/ssrn.3550025. [03.03.2020].

63. Baig AM, et al. Evidence of the COVID-19 virus targeting the CNS: Tissue distribution, host-virus interaction, and proposed neurotropic mechanisms. ACS Chem Neurosci 2020; 11: 995-8.

64. Mannan BA, et al. Evidence of the COVID-19 virus targeting the CNS: Tissue distribution, host-virus interaction, and proposed neurotropic mechanisms. ACS Chem Neurosci 2020; 11: 995-98.

65. Lechien JR, et al. Olfactory and gustatory dysfunctions as a clinical presentation of mild-to-moderate forms of the coronavirus disease (COVID-19): a multicenter European study. Eur Arch Otorhinolaryngol 2020. https://doi. org/10.1007/s00405-020-05999-5
66. Xinhua.net. Beijing hospital confirms nervous system infections by novel coronavirus. URL: http://www. xinhuanet.com/english/2020-03/05/c_138846529.htm. [05.03.2020].

67. Poyiadji N, et al. COVID-19-associated acute hemorrhagic necrotizing encephalopathy: CT and MRI features. Radiology 2020; Mar 31. [Epub ahead of print].

68. LiYC, et al. The neuroinvasive potential of SARS-CoV2 may play a role in the respiratory failure of COVID-19 patients. J Med Virol 2020; Feb 27. [Epub ahead of print].

69. Zhao $\mathrm{H}$, et al. Guillain-Barré syndrome associated with SARS-CoV-2 infection: causality or coincidence? Lancet Neurol 2020; Apr 1. [Epub ahead of print]

70. Carod-Artal FJ. Complicaciones neurológicas por coronavirus y COVID-19. Rev Neurol 2020;70 (09):311-322 doi: $10.33588 /$ rn.7009.2020179

71. Liu W, et al. COVID-19: Attacks the 1-Beta Chain of Hemoglobin and Captures the Porphyrin to Inhibit Human Heme Metabolism Chem Rxiv 2020. https://doi.org/10.26434/ chemrxiv.11938173.v7 